\title{
Serum Vitamin D Deficiency in NICU Hospitalized Neonates and Its Association With Neonatal Outcomes
}

\author{
Ziba Mosayebi; M.D. ${ }^{1}$, Setareh Sagheb; M.D. ${ }^{2}$, Mahsa Mirzendedel; M.D. ${ }^{3}$, \\ Amir Hossein Movahedian; M.D. ${ }^{4}$
}

1 Maternal, Fetal and Neonatal Research Center, Tehran University of Medical Sciences, Tehran, Iran 2 Department of Neonatology, Shariati Hospital, Tehran University of Medical Sciences, Tehran, Iran

3 Children's Medical Center, Tehran University of Medical Sciences, Tehran, Iran

4 Bahrami Children's Hospital, Tehran University of Medical Sciences, Tehran, Iran

Received December 2020; Revised and accepted April 2021

\begin{abstract}
Objective: Vitamin D deficiency is a major health problem in all age groups. In the present study, we aimed to determine the prevalence of vitamin $\mathrm{D}$ deficiency in neonates hospitalized in an intensive care unit (NICU) and its association with clinical neonatal outcomes.

Materials and methods: A prospective cross-sectional study was carried out on all neonates hospitalized in the NICU of Children's Medical Center over a period of one year (January-December 2018). Immediately on admission, a serum sample for vitamin D measurement was obtained with another routine blood sampling. Demographic and clinical data including sex, gestational age, the season of birth, serum levels of vitamin $D$ and calcium, the causes of hospitalization, age at admission and neonatal outcomes including length of hospital stay and mortality during hospitalization were assessed. Results: One hundred neonates entered the study. Vitamin D deficiency and insufficiency were present in $95 \%$ of neonates. There was a significant association between vitamin $\mathrm{D}$ status and birth during winter $(p=0.014)$; hypocalcemia $(p=0.025)$ and older age at NICU admission $(p<0.001)$. The mean value of vitamin $D$ in term neonates was significantly lower than in preterm neonates $(p=0.031)$. There were no correlations between length of hospital stay and neonatal mortality rate with vitamin $D$ status $(p=0.876)$.

Conclusion: Vitamin D deficiency and insufficiency were highly prevalent among NICU patients. Maternal vitamin D supplementation during pregnancy may prevent or reduce the risk of low levels of vitamin $D$ in neonates.
\end{abstract}

Keywords: Newborn; Neonatal Intensive Care Units; Vitamin D

\section{Introduction}

Vitamin D a fat-soluble vitamin is important for bone metabolism and calcium/phosphorus homeostasis. It has

\section{Correspondence:}

Dr. Amir Hossein Movahedian

Email:movahedian.ah@gmail.com a significant role in cell proliferation, differentiation, apoptosis and immune modulation. Vitamin D receptors (VDR) are expressed in many cells and tissues throughout the body $(1,2)$. Vitamin D is transmitted vertically and is vital for embryo and fetus development including, implantation, placental function, fetal skeletal maturation and general growth (2-5).

Copyright @ 2021 Tehran University of Medical Sciences. Published by Tehran University of Medical Sciences.

This work is licensed under a Creative Commons Attribution-Noncommercial 4.0 International license (https://creativecommons.org/licenses/by-nc/4.0/). Noncommercial uses of the work are permitted, provided the original work is properly cited. 
Vitamin D deficiency is a major health problem. It is estimated that one billion people are suffering from vitamin D deficiency all over the world (6). Pregnant and lactating women are among the high risk groups for developing vitamin D deficiency. The prevalence of vitamin D deficiency in pregnant women in Middle Eastern countries is high and is estimated to be $60-80 \%(7,8)$. Among Iranian pregnant women, the prevalence rates of vitamin D deficiency have been demonstrated as $78 \%, 76 \%, 70.4 \%$ and $69.2 \%$ by several studies (9). Deficiency of vitamin D in pregnant women decreases the transfer of this vitamin through the placenta and at birth (10-12). Since there is a positive and significant correlation between maternal and neonatal vitamin D serum levels, it seems that neonates could be highly affected by vitamin D deficiency related adverse effects.

In previous studies, low levels of vitamin D have been documented in adult patients admitted to intensive care units (ICUs). This deficiency was associated with more severe illness, adverse short and long term clinical outcomes and even mortality (13-15). Recently, some researches from pediatric intensive care units (PICUs) have demonstrated that vitamin $\mathrm{D}$ deficiency is also a common problem in critically ill children, ranging 30 to $70 \%$ (6). Few studies described the association between vitamin D deficiency and illness severity on admission, need for vasopressors and a longer PICU stay $(16,17)$. Whereas, Rippel et al did not find any association between low levels of vitamin $\mathrm{D}$ and length of stay or survival rate in critically ill children (18).

To the best of our knowledge, there is limited data on vitamin D status and its impact on newborn infants admitted to neonatal intensive care units (NICU) in Iran. This study aimed to investigate the prevalence of vitamin D deficiency and its association with clinical outcomes in neonates hospitalized in NICU.

\section{Materials and methods}

Study design: A prospective hospital based crosssectional descriptive study was carried out in the NICU of Children's Medical Center affiliated to Tehran University of Medical Sciences (Tehran-Iran) over a period of one year (January-December 2018). All the neonates with medical and surgical diseases hospitalized in NICU were enrolled in this study. Neonates without written parental consent, those who received large doses of vitamin $\mathrm{D}$ or had no acceptable plasma specimen for vitamin D measurement were excluded. The subjects were breast fed before admission.

Immediately on admission, serum sample for vitamin D measurement was obtained along with routine blood sampling, thus the impact of the affecting factors was minimized. Serum vitamin D and calcium levels were measured by Electrochemiluminescence immunoassay and Calcium Assay kit (colorimetric) methods, respectively. Vitamin D deficiency, insufficiency and sufficiency were defined as serum $25(\mathrm{OH})$ vitamin $\mathrm{D}<20 \mathrm{ng} / \mathrm{ml}$, $20-30 \mathrm{ng} / \mathrm{ml}$ and $>30 \mathrm{ng} / \mathrm{ml}$, respectively $(19,20)$. Serum Calcium less than $8 \mathrm{mg} / \mathrm{dL}$ was also considered as hypocalcemia (21). Confounding factors that could have an impact on calcium status such as serum levels of albumin, phosphate and magnesium or acid-base disorders have been considered and ruled out in the subjects. Regarding financial issues, we were not able to measure serum vitamin D level in their mothers at the same time. Demographic and clinical data of neonates including sex, gestational age, and the season of birth, serum levels of vitamin D and calcium, causes of hospitalization, age at hospital admission were recorded. Association between vitamin D levels and neonatal clinical outcomes including length of hospital stay and mortality rate during hospitalization were assessed.

Sample size: Based on Madden et al. study (17), with a prevalence of $41 \%$ for vitamin D deficiency and by using the following formula, the required sample size with a power of $80 \%$ and an alpha error of 0.05 , were 92 subjects.

$$
\begin{gathered}
\mathrm{N}=\mathrm{Z}^{2} \mathrm{P}(1-\mathrm{P}) / \mathrm{d} 2=92 \\
Z=1.96, \mathrm{P}=0.41, d=0.1
\end{gathered}
$$

Ethical considerations: Ethics approval was obtained from the institutional review board of Tehran University of Medical Sciences according to the Helsinki declaration. All participants' parents gave written consent before enrollment. Participants' data were considered confidential and no extra cost was imposed on our participants.

Data Analysis: Analyses were statistically performed by using the software package SPSS Version 18. Quantitative and qualitative variables were reported by mean $\pm \mathrm{SD}$ and percent, respectively. Independent Student t, Chi-square, and Bivariate Correlation tests were used for determining associations between vitamin D serum concentration and different variables. The Kaplan-Meier analysis was also performed to analyze the correlations between variables and the neonatal mortality rate. 
The level of significance was considered as $\mathrm{P}<0.05$.

\section{Results}

Of the 100 neonates admitted to the NICU during the study period, $60 \%$ were female and $40 \%$ were male. Among them 59\% were term and $41 \%$ were preterm. The mean \pm SD birth weight was $2158 \pm 826.46$ grams. The causes of hospitalization in $77 \%$ were medical and $23 \%$ were surgical diseases. The mean $\pm \mathrm{SD}$ age at hospital admission were $64.60 \pm 33.59$ days in the sufficient group, $11.09 \pm 14.04$ days in the insufficient group and $6.72 \pm 9.54$ days in the deficient group. The length of hospital stay was $11 \pm 9.82,12.80 \pm 7.99$ and $13.81 \pm 12.70$ days in sufficient, insufficient and deficient groups respectively. Forty-one $(41 \%)$ cases were born in spring and summer and $59(59 \%)$ were born in fall and winter.

From the studied neonates, 5 had normal vitamin D level, 58 had insufficient vitamin D level and 37 had vitamin D deficiency. So, vitamin D deficiency and insufficiency were present in $95 \%$ of our patients. The mean \pm SD serum level of vitamin $\mathrm{D}$ was $14.83 \pm 18.96 \mathrm{ng} / \mathrm{ml}(\mathrm{Min}=2, \mathrm{Max}=150 \mathrm{ng} / \mathrm{ml})$ in our patients. The mean \pm SD values between hospitalized neonates due to medical and surgical causes were $15.01 \pm 19.95$ and $14.26 \pm 15.61 \mathrm{ng} / \mathrm{ml}$ respectively. About $35 \%$ of the neonates had hypocalcemia. The mean \pm SD serum calcium level was $8.34 \pm 1.25 \mathrm{mg} / \mathrm{dL}$ $(\mathrm{Min}=2, \mathrm{Max}=10.8)$. The mean $\pm \mathrm{SD}$ values among neonates with medical and surgical disorders were $8.27 \pm 1.34$ and $8.55 \pm 0.91 \mathrm{mg} / \mathrm{dL}$ respectively.
Associations between neonatal vitamin D status and demographic and clinical characteristics: The baseline demographic and clinical characteristics of the neonates according to vitamin D status were shown in Table 1 . We did not find any association between serum vitamin D level and neonatal sex. The mean serum value of vitamin $\mathrm{D}$ was similar among both gender $(p=0.305)$. There were no significant differences in the neonatal vitamin $\mathrm{D}$ status regarding medical or surgical causes of admission ( $\mathrm{p}=0.764)$. Different etiologies for NICU admission are demonstrated in Table 2. Moreover, longer length of hospital stay was not associated with lower levels of vitamin $\mathrm{D}(\mathrm{p}=0.864)$.

A significant association was observed between vitamin D status and season of birth. Most of the neonates with vitamin $\mathrm{D}$ deficiency were born in winter $(\mathrm{p}=0.014)$. More than half of the neonates (54.3\%) with vitamin D deficiency were also hypo calcemic $(p=0.025)$. Neonates with sufficient levels of vitamin $\mathrm{D}$ had a higher mean age at the time of admission compared to deficient and insufficient groups. This difference between the mean age of admission and vitamin $\mathrm{D}$ status in newborn infants was significant $(p<0.001)$. However, there was no significant difference between the term and preterm neonates regarding the prevalence of vitamin $\mathrm{D}$ deficiency, insufficiency and sufficiency ( $p=0.185$ ), but the mean value of vitamin $\mathrm{D}$ in term neonates was significantly lower than preterm neonates $(10.74 \mathrm{ng} / \mathrm{ml}$ vs. $20.63 \mathrm{ng} / \mathrm{ml} ; \mathrm{p}=0.031)$.

Table 1: Correlations between vitamin D status and neonatal characteristics in NICU hospitalized neonates

\begin{tabular}{|c|c|c|c|c|}
\hline Variables & $\begin{array}{c}\text { Vitamin D Sufficient } \\
(\mathrm{n}=5)\end{array}$ & $\begin{array}{c}\text { Vitamin D Insufficient } \\
(\mathrm{n}=58)\end{array}$ & $\begin{array}{c}\text { Vitamin D Deficient } \\
(\mathbf{n}=37)\end{array}$ & P value \\
\hline $\operatorname{Sex}[\mathrm{n}(\%)]$ & & & & 0.264 \\
\hline Female & $3(5)$ & $31(51.7)$ & $26(43.3)$ & \\
\hline Male & $2(5)$ & $27(67.5)$ & $11(27.5)$ & \\
\hline Gestational age $[\mathrm{n}(\%)]$ & & & & 0.185 \\
\hline Gestational age $<37$ weeks & $4(9.8)$ & $22(53.7)$ & $15(36.6)$ & \\
\hline Gestational age $\geq 37$ weeks & $2(5)$ & $2(5)$ & $2(5)$ & \\
\hline Causes of hospitalization [n (\%)] & & & & 0.764 \\
\hline Medical & $4(5.2)$ & $46(59.7)$ & $27(35.1)$ & \\
\hline Surgical & $1(4.3)$ & $12(52.2)$ & $10(43.5)$ & \\
\hline Season of birth [n (\%)] & & & & 0.014 \\
\hline Spring & $2(40)$ & $6(10.3)$ & $5(13.5)$ & \\
\hline Summer & $0(0)$ & $24(41.4)$ & $4(10.8)$ & \\
\hline Fall & $2(40)$ & $16(27.6)$ & $13(35.1)$ & \\
\hline Winter & $1(20)$ & $12(20.7)$ & $15(40.5)$ & \\
\hline Age at admission (days)* & $64.60 \pm 33.59$ & $11.09 \pm 14.04$ & $6.72 \pm 9.54$ & $<0.001$ \\
\hline Length of hospital stay* (days) & $11.00 \pm 9.82$ & $12.80 \pm 7.99$ & $13.81 \pm 12.70$ & 0.864 \\
\hline Calcium status [n (\%)] & & & & 0.025 \\
\hline Normal & $3(4.6)$ & $44(67.7)$ & $18(27.7)$ & \\
\hline Low & $2(5.7)$ & $14(40)$ & $19(54.3)$ & \\
\hline
\end{tabular}


Table 2: The causes of admission according to vitamin $D$ status in NICU hospitalized neonates

\begin{tabular}{lccc}
\hline Variables & Sufficient $(\mathbf{n}=\mathbf{5})$ & Insufficient $(\mathbf{n = 5 8})$ & Deficient $(\mathbf{n = 3 7})$ \\
Medical causes (n=77) & & 4 & 3 \\
$\quad$ Hyperbilirubinemia & - & 9 & 6 \\
Respiratory distress syndrome & 2 & 3 & 2 \\
Metabolic disorders & - & 9 & 5 \\
Seizure disorders & - & 3 & 1 \\
Sepsis & - & 4 & 1 \\
Electrolyte imbalance & - & 2 & 4 \\
Hypoglycemia & - & 4 & 1 \\
Necrotizing enterocolitis & - & 6 & 2 \\
Congenital heart diseases & - & - & - \\
Neonatal diabetes & 1 & 3 & 2 \\
Others & - & & 7 \\
Surgical causes (n=23) & & 8 & 3 \\
Intestinal atresia & 1 & 3 & - \\
Myelomeningocele & - & - & \\
Urologic disorders & 1 & & \\
\hline
\end{tabular}

\begin{abstract}
Associations between neonatal mortality, demographic characteristics and Vitamin $D$ status: Of all neonates, 5 patients ( 2 females and 3 males) died. Causes of death were clinical sepsis in three, necrotizing enterocolitis in one and congenital heart disease (single ventricle) in the other patient. Two were preterm. All of them had deficient or insufficient levels of vitamin D and two had hypocalcemia as well. Kaplan-Meier analysis indicated no correlation between neonatal mortality with vitamin $\mathrm{D}$ status $(\mathrm{p}=0.876)$ or serum calcium level $(\mathrm{p}=0.874)$. There was no significant correlation between neonatal mortality with sex and gestational age $(p>0.05)$. All of the neonates with surgical underlying diseases survived during the study period.
\end{abstract}

\section{Discussion}

The result of the present study showed that the prevalence of vitamin D deficiency and insufficiency were $37 \%$ and $58 \%$ in the neonates hospitalized in the NICU. The majority of neonates (95\%) had abnormal levels of vitamin $\mathrm{D}$ at the time of admission. In the study held by Bhimji et al. among neonates admitted to the neonatal ward of a tertiary care hospital, about $80 \%$ of the neonates had vitamin D deficiency (22). A prevalence of $94 \%$ vitamin D deficiency was also reported in Jordanian newborns. This low level of vitamin D was not associated with NICU admission (11). Chacham et al. conducted an observational study at a tertiary care center on infants aged equal or less than one-year-old to evaluate the prevalence of vitamin D deficiency. $80 \%$ of the studied population was neonates and the prevalence of vitamin D deficiency was $79 \%$ among them (23). Based on the results of a study from Iran, of 522 enrolled newborns, 93.3\% had mild to severe vitamin D deficiency at birth (24). Another research from Saudi Arabia reported vitamin D deficiency in $86 \%$ of the studied newborns (25). Tanbakuchi et al. observed a low level of vitamin D in $76.6 \%$ of term and $90 \%$ of preterm Iranian newborn infants at the birth time (12). Previous Investigations from Albany and Australia found vitamin D deficiency or insufficiency in $80 \%$ of preterm infants with a birth weight of less than $1500 \mathrm{gr}$ (26) and in $35.7 \%$ of preterm neonates who were admitted at NICU (27), respectively. The high prevalence of the low levels of vitamin $\mathrm{D}$ in our patients similar to others could be attributed to maternal vitamin D status. Various factors like mother's clothing style, nutritional diet and prenatal vitamin D supplements, geographic region, sunshine exposure, ethnicity, genetic factors, underlying illnesses and different laboratory cut-offs are possible reasons for the high prevalence of vitamin D deficiency in mothers $(8,28,29)$.

In our patients, a significant association was present between serum vitamin $\mathrm{D}$ levels and the age of admission at NICU. Lower levels of vitamin D were observed in younger neonates and sufficient levels in older newborn infants. This finding may indicate a preexisting vitamin $\mathrm{D}$ deficiency in pregnant mothers. By advancing feeding and supplementing vitamins including vitamin $\mathrm{D}$, a sufficient level might be achieved in older infants. Panda et al revealed an increasing trend in vitamin D levels in preterm infants admitted to NICU by 
vitamin D supplementation. The median vitamin D level within the first 3 days of life was $57 \mathrm{nmol} / \mathrm{L}$ which increased to $63.5 \mathrm{nmol} / \mathrm{L}$ at 3-4 weeks and 103 $\mathrm{nmol} / \mathrm{L}$ between 6-8 weeks. This intervention resulted in a decrease in the prevalence of low levels of vitamin D from $36 \%$ at birth to $17 \%$ at 3-4 weeks and to $10 \%$ at $6-8$ weeks (27).

Our findings showed that neonatal vitamin D status was significantly correlated with the season of birth. Of all the vitamin $\mathrm{D}$ deficient neonates, the majority of them were born in winter. This association between vitamin D status and season of birth was reported by Madden et al. They showed that neonates who were admitted during summer had higher levels of vitamin D compared to those admitted in other seasons. The least levels of vitamin pertained to subjects who were admitted during fall or winter (17). The correlation between vitamin D levels and season of birth was also reported by Korj-Bulos et al. They showed low levels of vitamin $\mathrm{D}$ in neonates who were born during winter months (11). Other studies demonstrated higher prevalence of vitamin $\mathrm{D}$ deficiency in colder seasons $(9,11)$. However, some other researchers did not find any significant differences between season of birth and the vitamin D level $(30,31)$. It seems seasonal variation and changes in sunlight exposure are some environmental factors that may affect serum vitamin D level.

According to our data, a significant correlation between neonatal serum vitamin $\mathrm{D}$ and total calcium level was present. The majority of our patients with low levels of vitamin D were hypo calcemic as well. This significant correlation between neonatal vitamin D status and serum calcium level was also stated by another study from Iran (24). Consistent with our findings, McNally et al. have demonstrated a lower level of vitamin D was associated with hypocalcemia (32). Other studies reported the lowest concentration of ionized calcium with lower levels of vitamin D in PICU patients (18). Vitamin D is essential for calcium and phosphorus hemostasis. Low levels of this vitamin in pregnant mothers may affect placental calcium transfer and influences neonatal calcium level (24). Moreover, low levels of vitamin D may result in poor intestinal calcium absorption.

In our study, the mean value of vitamin $\mathrm{D}$ in term neonates was significantly lower than preterm neonates. In line with our study, Fallahi et al. from Iran reported a lower level of vitamin D in term neonates compared to the preterm infants (13.39 vs. 13.91 $\mathrm{ng} / \mathrm{ml}$ ), however, the difference was not significant $(p=0.850)$ (33). This finding was supported by Thomas et al who found no difference between the vitamin D levels in term and preterm infants (5). Other studies also observed no significant difference in vitamin $\mathrm{D}$ status among term and preterm newborn infants (2). Therefore, regardless of gestational age vitamin D deficiency can affect both term and preterm neonates $(2,5,33)$. However, there are several studies in contrary to our results that indicated a lower level of vitamin D among preterm infants compared to their term counterparts $(14,34,35)$.

We find no significant difference regarding neonatal vitamin D levels between medical and surgical patients. Compatible with our results, Arson et al. did not find any correlation between vitamin $\mathrm{D}$ levels and the causes of hospitalization (15). In Rippel et al. study, low levels of vitamin D were more common in cardiac patients than noncardiac cases (40\% vs 22\%). Vitamin D deficiency was observed in $40.5 \%$ of postoperative cardiac patients (18). Cardiac bypass can lower the vitamin D level. Madden et al did not find lower levels of vitamin D in children with confirmed or suspected sepsis in comparison with other critically ill children admitted to PICU except for severe septic shock (17). Respiratory morbidities including respiratory distress syndrome and bronchopulmonary dysplasia were more common in preterm infants with severe vitamin $\mathrm{D}$ deficiency described by Kim et al (2). Another study demonstrated a high prevalence of vitamin D deficiency in critically ill asthmatic children (19). Various responses to acute stress and severe illnesses besides geographic and ethnic differences could explain different findings between studies.

The absence of a significant association between duration of NICU hospitalization and serum vitamin D status was compatible with multiple studies. Rey et al. (30) and Rippel et al. (18) found no association between vitamin D deficiency and ICU or hospital length of stay. Somewhat different results were demonstrated by McNally et al. (16) and Sankar et al (6) which longer length of stay was associated with vitamin D deficiency. Kim et al. reported the average duration of NICU hospitalization in vitamin D deficient group was significantly longer than vitamin D insufficient or sufficient groups (2). Another study demonstrated a significant correlation between neonatal vitamin D levels with the duration of NICU hospitalization (36). Various causes and severity of diseases upon admission in ICUs may describe these variations between different studied patients. 
We did not find any association between serum vitamin D status with neonatal mortality. Similar to our findings, Azim et al. and other studies reported no association between vitamin D status and mortality rate among hospitalized critically ill patients $(13,18)$. Rey did not find any differences in risk of mortality scores between vitamin $\mathrm{D}$ deficient patients and healthy children (30). McNally et al. have shown that the survival of an infant was more affected by the type and severity of underlying disorders rather than vitamin D status (32). It has been suggested low levels of vitamin $\mathrm{D}$ are a biomarker associated with infection severity, organ dysfunction and mortality in ill patients.

Our study was one of the scarce studies that evaluated the vitamin $\mathrm{D}$ status in neonates admitted to NICU but it had several limitations. The sample size was relatively small. Lack of a control group was the most important limitation of our study, so we were not able to compare the patients who were vitamin $\mathrm{D}$ deficient with those who were not deficient. It was a single center study, so the results could not be generalized to the other centers with the different populations. Moreover, maternal vitamin D level was not measured because of the limited financial resources, thus the impact of maternal vitamin D status on neonatal vitamin level was not clear. We did not measure ionized calcium and parathyroid hormone in our patients as well.

Further multicenter researches with a larger sample size and long term follow up to determine the impact of vitamin D on neonatal clinical outcomes and mortality rate is required.

\section{Conclusion}

The present study demonstrated that vitamin D deficiency and insufficiency were common among neonates admitted to NICU. Low levels of vitamin D were not associated with neonatal outcomes including longer hospital stay or increased mortality rate during hospital admission. In order to prevent or reduce the high prevalence of low levels of vitamin D in neonates, it is reasonable to reconsider the recommendation of vitamin D supplementation for mothers during pregnancy. Moreover, there may be a role for routine evaluation of the vitamin D status in all neonates for prompt diagnosis and appropriate treatment of any suboptimal levels of vitamin D.

\section{Conflict of Interests}

Authors have no conflict of interests.

\section{Acknowledgments}

We acknowledge NICU staff for their kindly collaboration in this study.

\section{References}

1. Agarwal S, Kovilam O, Agrawal DK. Vitamin D and its impact on maternal-fetal outcomes in pregnancy: A critical review. Crit Rev Food Sci Nutr 2018; 58: 755-69.

2. Kim I, Kim SS, Song JI, Yoon SH, Park GY, Lee YW. Association between vitamin D level at birth and respiratory morbidities in very-low-birth-weight infants. Korean J Pediatr 2019; 62: 166-72.

3. Eremkina AK, Mokrysheva NG, Pigarova EA, Mirnaya SS. Vitamin D: effects on pregnancy, maternal, fetal and postnatal outcomes. Ter Arkh 2018; 90:115-7.

4. Baqai S, Siraj A,Imran R. Association of vitamin-D insufficiency during pregnancy with maternal \& perinatal morbidity and mortality. Pak Armed Forces Med J 2020; 70: 323-7.

5. Thomas DJ, Khan HU, Paul S, Jaidev MD, Hegde P. A study on vitamin D levels in preterm and term neonates and their mothers. International Journal of Contemporary Pediatrics 2020; 7: 387-92.

6. Sankar J, Lotha W, Ismail J, Anubhuti C, Meena RS, Sankar MJ. Vitamin D deficiency and length of pediatric intensive care unit stay: a prospective observational study. Ann Intensive Care 2016; 6: 3.

7. Behjat Sasan S, Zandvakili F, Soufizadeh N, Baybordi E. The Effects of Vitamin D Supplement on Prevention of Recurrence of Preeclampsia in Pregnant Women with a History of Preeclampsia. Obstet Gynecol Int 2017; 8249264.

8. Rostami M, Ramezani Tehrani F, Simbar M, Hosseinpanah F, Alavimajd H. Rationale and Design of Khuzestan Vitamin D Deficiency Screening Program in Pregnancy: A Stratified Randomized Vitamin D Supplementation Controlled Trial. JMIR Res Protoc 2017; 6: e54.

9. Sepandi M, Smailzadeh S, Hosseini M, Hashemi SR, Abbaszadeh S, Alimohamadi Y, et al. Prevalence of vitamin D deficiency among Iranian pregnant women. Nutrition and Dietary Supplements 2020; 12: 97-102.

10. Mirzaei F, Amiri Moghadam T, Arasteh P. Comparison of serum 25-hydroxy vitamin D levels between mothers with small for gestational age and appropriate for gestational age newborns in Kerman. Iran $\mathbf{J}$ Reprod Med 2015; 13: 203-8.

11. Khuri-Bulos N, Lang RD, Blevins M, Kudyba K, Lawrence L, Davidson M, et al. Vitamin D Deficiency among Newborns in Amman, Jordan. Glob J Health Sci 2013; 6:162-71. 
12. Tanbakuchi B, Taheri F, Zardast M, Ramazani A. Effect of Vitamin D Supplementation on Vitamin D Levels of Term and Preterm Neonates and their Mothers: A Clinical Trial Study. International Journal of Pediatrics 2019; 7: 10311-22.

13. Azim A, Ahmed A, Yadav S, Baronia AK, Gurjar M, Godbole MM, et al. Prevalence of vitamin D deficiency in critically ill patients and its influence on outcome: experience from a tertiary care centre in North India (an observational study). J Intensive Care 2013; 1: 14.

14. Venkatram S, Chilimuri S, Adrish M, Salako A, Patel M, Diaz-Fuentes G. Vitamin D deficiency is associated with mortality in the medical intensive care unit. Crit Care 2011; 15: R292.

15. Arnson Y, Grinzauz I, Itzhaky D, Amital H. Vitamin D deficiency is associated with poor outcomes and increased mortality in severely ill patients. QJM 2012; 105: 633-9.

16. McNally JD, Nama N, O'Hearn K, Sampson M, Amrein K, Iliriani K, et al. Vitamin D deficiency in critically ill children: a systematic review and metaanalysis. Crit Care 2017; 21: 287.

17. Madden K, Feldman HA, Smith EM, Gordon CM, Keisling SM, Sullivan RM, et al. Vitamin D Deficiency in Critically Ill Children. Pediatrics 2012; 130: 421-8.

18. Rippel C, South M, Butt ww, Shekerdermian LS. Vitamin D status in critically ill children. Intensive Care Med 2012; 38: 2055-62

19. Hebbar KB, Wittkamp M, Alvarez JA, McCracken CE, Tangpricha V. Vitamin D Deficiency in Pediatric Critical Illness. J Clin Transl Endocrinol 2014; 1:170-5.

20. Ringe JD, Kipshoven C. Vitamin D-insufficiency. An estimate of the situation in Germany. Dermatoendocrinol 2012; 4: 72-80.

21. Chiruvolu A, Engle WD, Sendelbach D, Manning MD, Jackson GL. Serum calcium values in term and latepreterm neonates receiving gentamicin. Pediatr Nephrol 2008; 23: 569-74.

22. Bhimji KM, Naburi H, Aboud S, Manji K. Vitamin D status and associated factors in neonates in a resource constrained setting. Int J pediatr 2018: 9614975.

23. Chacham S, Rajput S, Gumurkar S, Mirza A, Saxena V, Daksinamurthy $S$, et al. Prevalence of Vitamin D Deficiency Among Infants in Northern India: A Hospital Based Prospective Study. Cureus 2020; 12: e11353.

24. Maghbooli Z, Hossein-Nezhad A, Shafaei AR, Karimi F, Madani FS, Larijani B. Vitamin D status in mothers and their newborns in Iran. BMC Pregnancy Childbirth 2007; 7 : 1 .

25. Al-Wassia H, Abo-Ouf N. Prevalence of vitamin D deficiency in mother-infant pairs in a tertiary hospital in the west coast of Saudi Arabia. Journal of Clinical Neonatology 2016; 5: 243-6.

26. Munshi UK, Graziano PD, Meunier K, Ludke J, Rios A. Serum 25 Hydroxy Vitamin D Levels in Very Low Birth Weight Infants Receiving Oral Vitamin D Supplementation. J Pediatr Gastroenterol Nutr 2018; 66: 676-9.

27. Panda M, McIntosh J, Chaudhari T, Kent AL. Do Maternal Vitamin D Levels Influence Vitamin D Levels in Preterm Neonates? International Journal of Pediatrics 2019; 5: 1-7.

28. Spiro A, Buttriss JL. Vitamin D: An overview of vitamin D status and intake in Europe A. Nutr Bull 2014; 39: 322-50.

29. Aly H, Abdel Hady H. Vitamin D and the Neonate: An Update. Journal of Clinical Neonatology 2015; 4:1-7.

30. Rey C, Sánchez-Arango D, López-Herce J, MartínezCamblor P, García-Hernándeze I, Prietof $\mathrm{B}$, et al. Vitamin D deficiency at pediatric intensive care admission. J Pediatr (Rio J) 2014; 90; 135-42.

31. Hosseinzadeh Z, Kazemian M, Mashak B, Torkmandi H, Badfar GH. Vitamin D status in pregnant women and their newborn in karaj. Int J Pediatr 2018; 6: 7117-27.

32. McNally JD, Menon K, Chakraborty P, Fisher L, Williams KA, Al-Dirbashi OY, et al. The Association of Vitamin D Status with Pediatric Critical Illness. Pediatrics 2012; 130: 429-36.

33. Fallahi M, Afjeh A, Saneifard H, Namazi N, Kazemian M, Tabatabaee Sh. Comparison of Vitamin D Level in Preterm and Term Infant-Mother Pairs: A Brief Study. Iranian Journal of Neonatology 2016; 7:31-6.

34. Burris HH, Van Marter LJ, McElrath TF, Tabatabai P, Litonjua AA, Weiss ST, et al. Vitamin D status among preterm and full term infants at birth. Pediatr Res 2014; 75: 7580 .

35. Monangi N, Slaughter JL, Dawodu A, Smith C, Akinbi HT. Vitamin D status of early preterm infants and the effects of vitamin D intake during hospital stay. Arch Dis Child Fetal Neonatal Ed 2014; 99: F166-8.

36. Boskabadi H, Mamoori G, Khatami F, Faramarzi R. Serum level of vitamin D in preterm infants and its association with premature-related respiratory complications: a case control study. Electron Physician 2018; 10: 6208-14.

Citation: Mosayebi Z, Sagheb S, Mirzendedel M, Movahedian AH. E Serum Vitamin D Deficiency in NICU Hospitalized Neonates and Its Association With Neonatal Outcomes. J Fam Reprod Health 2021; 15(2): 99-105. 